NBER WORKING PAPER SERIES

LABOR FORCE TRANSITIONS AND UNEMPLOYMENT

Kin B. Clark

Lawrence H. Surmers

Working Paper No. 277

April 1978

(Revised August 1978)

NATIONAL BUREAU OF ECONOMIC RESEARCH

1050 Massachusetts Avenue

Cambridge MA 02138

The research reported here is part of the NBER's research program in labor studies. Any opinions expressed are those of the authors and not those of the National Bureau of Economic Research. We are grateful to Barbara Job and Morris Newman of the Bureau of Labor Statistics and to Ralph Smith and Jean Vanski of the Urban Institute for making avallable unpublished data. David Ellwood made the fourth section possible by allowing us to make use of his 1976 May CPS file. We have profited from discussions with Gary Chamberlain, Martin Feldstein, Richard Freeman, and members of the Harvard Labor Economics Seminar. Much of the computational work was done by Michael Brown and James Poterba. Funds were provided by ASPER of the U.S. Department of Labor. 


\title{
SUMMARY
}

\section{Labor Force Transitions and Unemployment}

This paper challenges conventional views of unemployment. Its results suggest that failure to examine closely labor force transitions has led to a misleading picture of unemployment and the way the labor market functions in general. There are four main conclusions. First, labor force transitions are the principal determinant of fluctuations in employment and unemployment. We find that the vast majority of those newly employed come not from unemployment but from outside the labor force. Likewise, most spells of employment end with labor force withdrawal rather than unemployment. Second, traditional estimates of the duration of unemployment and the ease of job finding are seriously flawed by failure to take account of the 45 percent of all unemployment spel1s which end in labor force withdrawal. Third, re-entrant unemployment is to a large extent the result of job-ending followed by a brief spell outside the labor force. Many re-entrants would almost certainly be better classified as job losers and leavers completing long spells of unemployment rather than as entrants starting a new spell of unemployment. Fourth, it appears that many of those counted as out of the labor force are functionally indistinguishable from the unemployed.

\author{
Kim B. Clark \\ Lawrence H. Summers \\ National Bureau of \\ Economic Research \\ 1050 Massachusetts Ave. \\ Cambridge, MA 02138
}

(617) 868-3912 
Economists in recent years have come to treat unemployment as a dynamic phenomenon. This view holds that high unemployment rates are not the result of a shortage of jobs but of high turnover. Indeed, the high proportion of unemployment attributable to sources other than job loss has been emphasized repeatedly. ${ }^{1}$ The apparently short duration of unemployment spells has led many observers to downplay the welfare significance of unemployment. It has also been cited to support the view that jobs are readily available for those who really want them.

This paper re-examines the dynamics of the labor market using the BLS gross changes data. The results confirm the importance of high turnover, but suggest that the nature of this turnover has been badly misunderstood. While movements between employment and unemployment dominate the conventional image of labor market mobility, they in fact account for a small part of movements into and out of unemployment and employment. Most movements in fact involve either labor force entrance or exit. This has important implications for usual views about unemployment.

For example, our results indicate that calculation of completed spell lengths for the unemployed is deceptive. Many persons experience a spell of unemployment followed by a brief tenure outside the labor force, and an interval of "re-entrant" unemployment. While the official statistics capture two brief spells, the experience might better be viewed as a single lengthy spell of unemployment. Apart from this difficulty, the results suggest that focus on average spell length is likely to be quite misleading since most unemployment is attributable to the relatively few long spells. 
Modern views of unemployment place considerable emphasis on job search. Unemployed workers are portrayed as engaged in productive labor i.e., searching for the best possible use of their talents. We find that search by the unemployed can explain only a small part of labor market behavior. Most persons who find jobs were out of the labor force rather than unemployed in the preceding month. Likewise, most separations from employment involve withdrawal from the labor force rather than the decision to seek work. Contrary to the usual search theory view, a fairly high proportion of unemployment spells end in labor force withdrawal rather than employment.

An additional important implication of our results involves the interpretation of the official unemployment statistics. The extremely high rates of transition between unemployment and the not in the labor force state lead us to suspect that many persons in these two states are functionally indistinguishable. Many of the movements picked up by the official statistics are likely to be the result of inconsistent reporting of relatively consistent behavior rather than actual behavioral shifts. The paper is divided into six sections. In Section I, we document the importance of labor force transitions in determining levels of employment and unemployment. The second section examines in detail the characteristics of unemployment spells and demonstrates the importance of labor force withdrawal. The experience of those who withdraw from the labor force is considered in Section III. We derive estimates indicating that a very high proportion of those who withdraw from the labor force return relatively quickly. These estimates are shown to be consistent with the expressed intentions of those outside the labor force. In 
Section IV, we examine the characteristics of unemployed re-entrants, and show that much of this group may be viewed as completing longer spells of unemployment. The fifth section of the paper uses the annual Work Experience Survey to provide independent evidence corroborating the view put forth in preceding sections. Finally, Section VI discusses the implications of the results.

I

This study makes use of the BLS gross changes data to analyze the structure and dynamics of unemployment. ${ }^{2}$ From two-way tabulations of labor force status this month by labor force status last month, it is possible to find the number of individuals who moved, for example, from unemployment to employment during the last month. Since there are three possible labor market states (employment, unemployment, not-in-the-labor force), there are nine monthly flows which may be calculated.

We summarize the available information for each month in a $3 \times 3$ matrix of transition probabilities and a vector of three stocks. Thus, for each of several demographic groups we consider the matrix:

$$
P=\left[\begin{array}{ccc}
P_{\text {ee }} & \mathrm{P}_{\text {eu }} & \mathrm{P}_{\text {en }} \\
\mathrm{P}_{\text {ue }} & \mathrm{P}_{\text {uu }} & \mathrm{P}_{\text {un }} \\
\mathrm{P}_{\mathrm{ne}} & \mathrm{P}_{\mathrm{nu}} & \mathrm{P}_{\mathrm{nn}}
\end{array}\right]
$$

where, for example, $P_{\text {en }}$ represents the proportion of employed workers last month who were out of the labor force this month. Since a worker must always be in one of the three labor force states, the rows of $P$ sum to 1 . 
The focus of this study is on labor force transitions. It will therefore be convenient to define a state $\mathrm{L}$, for labor force, which includes both $E$ and $U$. Letting $F_{i j}$ represent the flow of workers into state $j$ from state $i$, it is clear that:

$$
\begin{aligned}
& F_{n l}=F_{n e}+F_{n u} \\
& F_{\text {ln }}=F_{\text {en }}+F_{\text {un }}
\end{aligned}
$$

The transition probabilities may then be represented as:

$$
\begin{aligned}
& P_{n 1}=P_{n e}+P_{n u} \\
& P_{1 n}=\frac{E_{-1}}{L_{-1}} P_{\text {en }}+\frac{U_{-1}}{L_{-1}} P_{\text {un }}
\end{aligned}
$$

The Importance of Labor Force Transitions

A striking feature of the data is the enormous magnitude of all the flows. ${ }^{3}$ In an average month between 1968 and 1976, about 4 percent of those in the labor force or 3.8 million people left the labor force and 4.0 million people entered. While the flows are greatest for teenagers, they are large even for prime age males. Close to 0.275 million men between the ages of 25 and 59 leave the labor force each month. A slightly smaller number enter each month. As one would expect, women have much higher flow probabilities than men, reflecting greater volatility in labor force participation.

The role of entrance and exit flows in explaining unemployment and employment is examined in Table 1 . It is instructive to consider the group with the greatest labor force attachment, prime-age males, 2559. Even though between 1968 and 1976 this group had an average participation rate of 92 percent, one-third of employment entrance occurred 


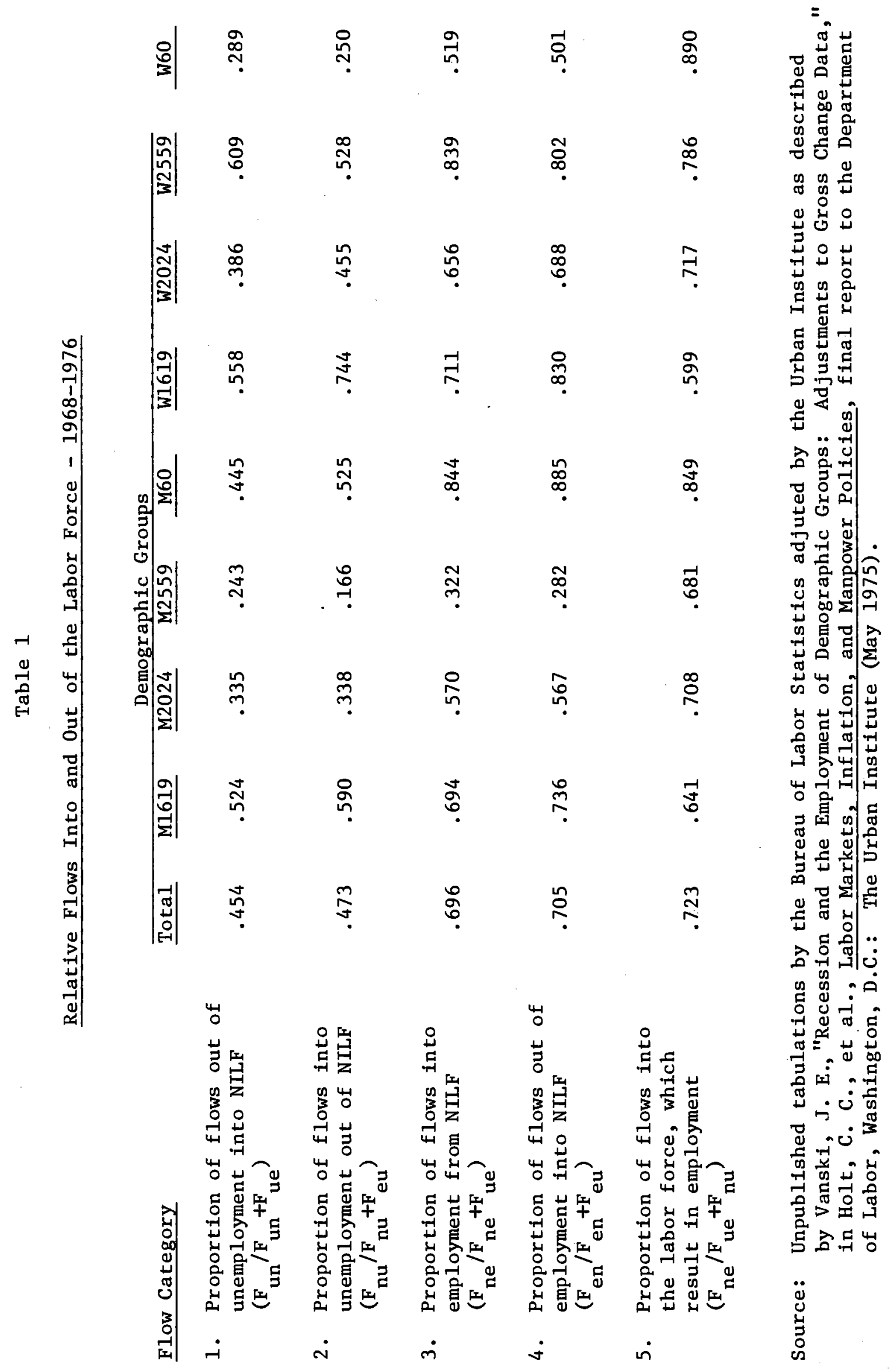


from outside of the labor force. Likewise, 28 percent of employment spells ended in labor force withdrawal. Similar relationships characterize unemployment. Almost 25 percent of unemployment spells end in labor force withdrawal. Other demographic groups are characterized by even greater flows into and out of the labor force. For adult women, 83.7 percent of all employment spells begin with labor force entrance, and 77.8 percent end in labor force withdrawal. For the total population, about $70 \%$ of entrances into employment occur without recorded unemployment, and a comparable proportion of employment spells end in withdrawal. Almost half of unemployment spells begin and end outside of the labor force.

\section{Duration of Completed Spells}

The tremendous volatility of labor force behavior may also be conveyed by examining the mean duration of completed spells in each of the states. Assuming a steady state, the mean duration of a completed spell in state $i$ is estimated as: ${ }^{4}$

$$
D_{i}=\frac{1}{1-P_{i i}}
$$

The mean duration of completed spells in the various states are presented in Table 2, for different demographic groups. The spells are surprisingly short. The average completed spell of employment lasts for only 21 months. For teenagers the figure is only 6 months. The typical duration of spells outside the labor force is even shorter, averaging about 15 months over the 1968-1976 period. For adult women, traditionally viewed as being only loosely attached to the labor force, the average duration of a spell of employment is 18 months, while the average spell outside the labor force 
Table 2

Mean Durations of Completed Spells - 1968-1976

(Data are in months)

\begin{tabular}{|c|c|c|c|c|c|}
\hline $\begin{array}{c}\text { Demographic } \\
\text { Group } \\
\end{array}$ & $\begin{array}{l}\text { Not in the } \\
\text { Labor } \\
\text { Force } \\
\left(D_{n}\right) \\
\end{array}$ & $\begin{array}{l}\text { Labor } \\
\text { Force } \\
\left(D_{1}\right) \\
\end{array}$ & $\begin{array}{c}\text { Emp loyment } \\
\left(\mathrm{D}_{\mathrm{e}}\right)\end{array}$ & $\begin{array}{l}\text { Unemp loyment } \\
\left(\mathrm{D}_{\mathrm{u}}\right)\end{array}$ & $\begin{array}{l}\text { Unemployment } \\
\text { with no } \\
\text { Withdrawal } \\
\left(D_{\text {ue }}\right) \\
\end{array}$ \\
\hline M1619 & 4.68 & 6.89 & 6.33 & 1.72 & 3.66 \\
\hline M2024 & 3.98 & 22.32 & 15.97 & 2.32 & 3.51 \\
\hline M2559 & 9.14 & 144.28 & 67.97 & 2.42 & 3.20 \\
\hline M60 & 31.90 & 19.99 & 19.20 & 2.52 & 4.69 \\
\hline W1619 & 6.54 & 5.78 & 5.82 & 1.70 & 3.93 \\
\hline W2024 & 11.07 & 16.86 & 13.87 & 2.49 & 4.07 \\
\hline W2559 & 16.84 & 18.18 & 18.25 & 2.18 & 5.60 \\
\hline W60 & 66.98 & 12.95 & 13.13 & 3.26 & 9.60 \\
\hline Total & 14.67 & 22.91 & 20.66 & 2.13 & 3.91 \\
\hline
\end{tabular}


lasts only 17 months. These figures imply that the average number of labor force entrances among women during their adult lifetime is 12 . For men the comparable number is 4 . Of course these high averages may result from extreme volatility on the part of a small part of the sample.

Unemployment spells are far shorter than spells in any of the other states. The average spell of unemployment lasted slightly over two months. 5 The duration was less for teenagers and women and somewhat greater for prime-age males. These durations would be much longer but for the fact that almost half of all workers leave unemployment by withdrawing from the labor force. In the final column of the table, the expected duration is computed for a hypothetical worker who is unwilling to withdraw from the labor force. As expected, such a worker has a much longer expected duration almost four months over the 1968-1976 period. This calculation also makes clear that labor force withdrawal, and not ease of transition into employment, accounts for teenagers' and women's apparently short unemployment spells. Teenagers and women unwilling to withdraw from the labor force have longer spells of unemployment than do prime-age males - e.g., 5.60 months for adult women, contrasted with 3.20 months for adult men.

The results in Tables 1 and 2 underscore the importance of labor force transitions in determining the frequency and duration of unemployment. The evidence suggests that estimates of the ease of job finding are overstated by failure to take into account the extent of labor force withdrawal. Spells of unemployment appear to be short because of frequent exit from the 
labor force. The estimates of duration in Table 2 ignore any hidden unemployment which occurs after labor force withdrawal. It seems plausible that at least some of those who end unemployment by leaving the labor force, do so because they are unable to find work. The calculations also ignore any hidden unemployment which occurred before labor force entry for those classified as re-entrants. These issues are taken up in subsequent sections. In the next section, we examine in more detail the way in which spells of unemployment end, by studying how the probability of labor force withdrawal is affected by the duration of and reason for unemployment.

This section examines the transition out of the unemployment state. We estimate hazard functions relating transitions to durations for various demographic groups. From the hazard function it is possible to generate density functions for the duration of completed spells ending in both employment and labor force withdrawal.

A hazard function relates the probability of exit from a state to the duration in the state. We generalize the notion usually employed in reliability theory by estimating separate hazard functions for exit to employment, and labor force withdrawal. The data come from the BLS gross change tabulations. They make available the flow from unemployment to employment, and unemployment to not in the labor force for those unemployed 0-4 weeks, 5-6 weeks, 7-10 weeks, 11-14 weeks, 15-26 weeks and 27+ weeks. To estimate hazard functions we fit curves by associating each range probability with the range midpoint. Various functional forms were tried with only slight effects on the conclusions. Results with the logarithmic 
form are presented here, since its performance was marginally superior. Thus, for each group for each year, we estimated the pair of equations:

$$
\begin{aligned}
& \mathrm{P}_{\text {ue }}=\alpha_{1}+\beta_{1} \ln \mathrm{t}+\mathrm{u}_{1} \\
& \mathrm{P}_{\text {un }}=\alpha_{1}+\beta_{2} \ln \mathrm{t}+\mathrm{u}_{2}
\end{aligned}
$$

where $t$ is the midpoint of the duration range, and $u_{1}$ and $u_{2}$ are error terms.

Typical results for men and women in 1969 and 1975 are presented in the appendix. The data quite clearly reject the simple Markov model. In virtually all cases the transition probabilities are dependent on duration. This could be the result of two quite different effects. First, it may be that the longer one is unemployed, the more difficult it becomes to find a job, and the less one can afford to take time off from job search and leave the labor force. Second, the observed duration dependence may be the result of heterogeneity. If each individual has a constant escape probability, those who remain unemployed longest will on average have the lowest escape probabilities, so the observed escape probability will decline with duration. 6

The observed hazard functions may be used to create monthly transition probabilities. This is done by assuming that each monthly transition probability may be approximated by the probability at the month's midpoint. Given $\mathrm{P}_{\text {un }}^{\mathrm{j}}$ and $\mathrm{P}_{\text {ue }}^{\mathrm{j}}$ for each month $\mathrm{j}$, the distribution of completed spells is easily computed. For example, the proportion of spells ending in labor force withdrawal after $t$ months is:

$$
h_{\text {un }}(t)=\prod_{j=1}^{t-1}\left(1-P_{\text {un }}^{j}-P_{\text {ue }}^{j}\right) P_{\text {un }}^{t}
$$

The proportion of spells of unemployment lasting more than $t$ periods, and ending in labor force withdrawal $\mathrm{H}_{\mathrm{un}}(t)$, is: 


$$
H_{u n}(t)=\sum_{j=t+1}^{\infty} h_{u n}(j)
$$

From the density functions, the mean lengths of completed spells, and the proportion of unemployment accounted for by spells of a given length may be computed. For example, the mean length of completed spells ending in labor force withdrawal, is:

$$
D_{u n}=\frac{\sum_{t=1}^{\infty} h_{u n}(t) t}{\sum_{t=1}^{\infty} h_{u n}(t)}
$$

Similar calculations yield the mean duration of completed spells ending in employment and of total completed spells.

The proportion of all unemployment accounted for by each type of spell may also be calculated from the density function of completed spells. If the flow into unemployment, $F_{u}$, is constant, the number of people unemployed at any moment is constant, and may be written as:

$$
\left.S_{u}=F_{u}{\underset{j=0}{\left(\sum\right.} H_{u n}}_{(j)}+\sum_{j=0}^{\infty} H_{u e}(j)\right)
$$

The proportion of unemployment due to, for example, those who will exit the labor force is:

$$
\pi_{\text {un }}=\frac{\left.\sum_{j=0}^{\infty} H_{u n}(j)\right)}{\left.\sum_{j=0}^{\infty} H_{u n}(j)+\sum_{j=0}^{\infty} H_{u e}(j)\right)}
$$

In a similar way, the proportion of unemployment accounted for by those with spells which will exceed $k$ weeks when they are completed can be calculated: 


$$
\pi=\frac{\sum_{j=k}^{\infty}\left(H_{u n}(j)+H_{u e}(j)\right)+(k)\left(H_{u n}(k)+H_{u e}(k)\right)}{\left.\sum_{j=0}^{\infty} H_{u n}(j)+\sum_{j=0}^{\infty} H_{u e}(j)\right)}
$$

In Table 3 we present various features of the distribution of completed spells derived from the estimated hazard functions. The results confirm the importance of exit unemployment. In both years 35 percent of male spells of unemployment ended in withdrawal. ${ }^{7}$ However, in 1975 exiters accounted for 46 percent of male unemployment. This is because the average duration of spells ending in exit was 2.82 months compared to 2.36 months for those ending in employment.

The results here confirm that most unemployment spells are very short. Even in 1975, when the unemployment rate reached a post-war high, close to 49 percent of all unemployment spells ended in less than a month for men, and 57 percent for women. However, these figures are quite misleading. Many short spells, 33 percent for men and 54 percent for women, end outside the labor force. More importantly, the fact that most spells are short does not imply that most unemployment is due to short spells. Longer spells obviously contribute disproportionately to total unemployment. Indeed, in 1975 for men, fully half of all unemployment was due to spells lasting over four months, and 34 percent was due to spells exceeding six months. The extremely cyclical character of long-term unemployment also stands out. For men, the proportion of unemployment due to spells lasting longer than three months was 34 percent in 1969 when the national unemployment rate was 3.5 percent, compared to 65 percent in 1975 when the national rate was 8.5 percent. 
Table 3

Estimated Exit and Entry Behavior and the Composition of Unemployment by Duration - Calculated from Functions in Appendix Table 1

\begin{tabular}{llll} 
Men & Women & Men & Women \\
1969 & $\underline{1969}$ & $\underline{1975}$ & $\underline{1975}$ \\
\hline
\end{tabular}

1. Proportion of spells of unemployment completed in one month or less

$\begin{array}{llll}0.67 & 0.78 & 0.49 & 0.57\end{array}$

2. Probability of exit from the labor force for those unemployed one month or less

$\begin{array}{llll}0.33 & 0.53 & 0.33 & 0.54\end{array}$

3. Probability of exit from the labor force for all unemployed (average)

$\begin{array}{llll}0.35 & 0.54 & 0.35 & 0.56\end{array}$

4. Proportion of unemployment accounted for by spells ending in exit from the labor force

$\begin{array}{llll}0.37 & 0.56 & 0.46 & 0.60\end{array}$

5. Mean duration of a completed spell - total (in months)

6. Mean duration of a completed spell for those who become employed

7. Mean duration of a completed spell for those who exit

8. Proportion of unemployment accounted for by spells ending in one month or less

$\begin{array}{llll}0.42 & 0.58 & 0.19 & 0.28\end{array}$

9. Proportion of unemployment accounted for by spells greater than

$$
\begin{array}{r}
3 \text { months } \\
4 \text { months } \\
5 \text { months } \\
6 \text { months } \\
9 \text { months } \\
12 \text { months }
\end{array}
$$

$\begin{array}{llll}0.34 & 0.19 & 0.65 & 0.52 \\ 0.20 & 0.09 & 0.52 & 0.38 \\ 0.12 & 0.04 & 0.42 & 0.27 \\ 0.07 & 0.02 & 0.34 & 0.20 \\ 0.02 & 0.00 & 0.18 & 0.08 \\ 0.00 & 0.00 & 0.09 & 0.03\end{array}$

10. Proportion of unemployment accounted for by spells of six months or more which end in exit

$\begin{array}{llll}0.03 & 0.01 & 0.14 & 0.13\end{array}$

11. Proportion of unemployment accounted for by spells of six months or more which end in employment 
An important feature of the results in Table 3 is the greater length of spells of unemployment which end in labor force withdrawal. This occurs because a disproportionate share (close to $60 \%$ ) of long-term unemployment spells end in labor force exit. It seems reasonable to conjecture that many persons who search for six months and then withdraw from the labor force are in some sense discouraged workers. If so, this suggests the possibility that there is a significant amount of hidden unemployment. This hypothesis is borne out by the evidence on discouraged workers . presented below.

Another possible explanation relies on the unemployment insurance system. It might be suggested that many people remain in the labor force only in order to collect benefits, and then withdraw when their benefits run out. While this pattern clearly does explain some of the high rates of labor force exit, it seems unlikely that it can explain most withdrawal. Most withdrawals occur among demographic groups, such as adult women and teenagers, in which UI benefits are least concentrated. Moreover, in 1975 and 1976 the UI benefit period was extended from 26 to 65 weeks with almost no effect on the rate of labor force exit.

Probability of Exit and Reason for Unemployment

The significance of unemployment spells ending in withdrawal depends on the type of unemployed persons who end their spells in this way. Unfortunately BLS does not make available exit data by reason for unemployment. From observed data on the stock of unemployment by reason, and the extent of labor force withdrawal, it is possible to draw some inferences. The procedure described below is an adaptation of the standard random coefficients regression technique. ${ }^{8}$ For each group of 
the unemployed, we allow the probability of leaving unemployment through withdrawal to depend on aggregate demand and a constant term. Thus,

$$
\text { Pexit }_{i t}=\alpha_{i}+\beta_{i} U_{t}+v_{i t}
$$

where $U$ represents aggregate demand, and the subscript $i$ represents the category of unemployment (losers, leavers, etc.). It is an identity that:

$$
\text { Pexit }_{t}=\Sigma s_{\text {it }} \text { Pexit }_{\text {it }}
$$

where the $s_{i t}$ represent the shares of the $i^{\text {th }}$ category in total unemployment. Combining equations (17) and (18) yields an equation which may be estimated from available data:

$$
\operatorname{Pexit}_{t}=\sum_{i} s_{i t} \alpha_{i}+\underset{i}{\left(\sum_{i t} s_{i}\right) U_{t}}+\sum_{i} s_{i t} v_{i t}
$$

in the actual estimation we modify equation (19) by adding seasonal dummies.

We have used the monthly data on the stock of unemployment to calculate the share of unemployment due to job losers, job leavers and labor force entrants. It has also been assumed that aggregate demand conditions may be proxied by a fixed weight distributed lag on the prime-age male unemployment rate $(\mathrm{RU})$. In the results reported here, $U=.4 \mathrm{RU}_{\mathrm{t}-1}+$ $.3 R U_{t-2}+.2 R U_{t-3}+.1 R U_{t-4}$.

The results of estimating equation (14) have been used to calculate average values of Pexit for job losers, leavers and labor force entrants. ${ }^{9}$ The results are reported in the top half of Table 4.10 In method I a separate value of $\beta$ was estimated for each group. Since the data fail to reject (i.e., $F(2,97)=1.39$ ), the hypothesis that all the $\beta_{i}$ are equal, we also present the estimates when this constraint is imposed. The numbers in parentheses are the standard errors of the estimates. ${ }^{11}$ 
Table $4 a$

Probability of Unemployment Ending in Labor Force Exit by Reason for Unemployment

$\underline{\text { Reason for Unemployment }}$

Method I

(separate $\beta_{i}$ )

Job losers

Job leavers

Entrants

Job exiters

.318
$(.150)$
.376
$(.057)$
.599
$(.058)$
.362

\begin{tabular}{l}
$\begin{array}{c}\text { Method II } \\
\left(\text { equal } \beta_{i}\right)\end{array}$ \\
\hline .333 \\
$(.150)$ \\
.403 \\
$(.056)$ \\
.568 \\
$(.053)$ \\
.386
\end{tabular}

Table 4b

Composition of Unemployment by Entry and Exit State

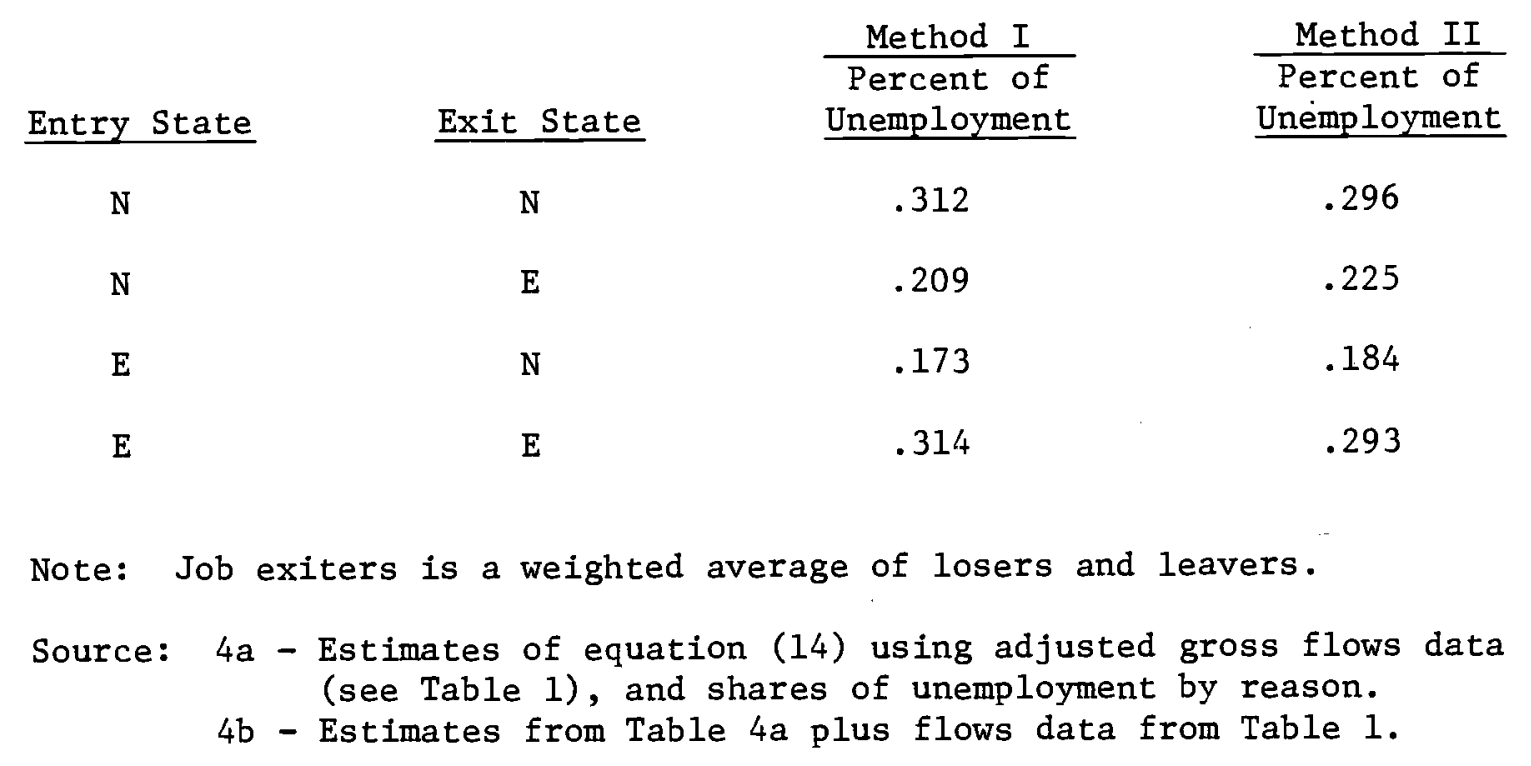


It appears clear from the evidence of Table 4 that labor force exit is most common among entrants. This is consistent with the finding noted earlier that Pexit is highest in the demographic groups, women and teenagers, where entrance is the largest cause of unemployment. While job leavers appear more likely to withdraw from the labor force than job losers, the difference is not statistically significant. In interpreting the values of Pexit for job losers and job leavers, it is important to recall that the vast majority of those who leave the employment state do not pass through the unemployment state. Hence, these figures greatly underestimate actual labor force withdrawal amongst job enders. In toto, close to 80 percent of job enders leave the labor force before getting a new job.

In the top half of the table we have derived estimates of the proportion of spells of unemployment which end in withdrawal for job exiters and entrants. From the flows data presented in Table 1 , it is possible to calculate the proportion of spells which begin in each of these ways. Combining this information, spells of unemployment may be decomposed into four categories based on initial and final state. That is, a spell may begin or end in state $N$, out of the labor force, and may begin or end in state $E$, employment. The decomposition of spells is presented in the bottom half of Table 4. The results confirm the importance of labor force transitions. Less than one-third of unemployment spells result from job change. In the first set of estimates, the most common type of unemployment spell does not either begin or end in employment. Both sets indicate that more than two-thirds of all unemployment spells begin or end outside of the labor force. 
This section has documented the importance of labor force transitions as a factor in determining unemployment. We have shown that the bulk of unemployment is accounted for by those in the process of entering or leaving the labor force. The welfare significance of this sort of unemployment depends critically on whether the withdrawals from and entries into the labor force are "voluntary" or are forced by economic exigencies. While the data are not available to fully answer this question, some information may be gleaned from a consideration of the permanence of labor force withdrawal. This issue is taken up in the next section.

\section{III}

This section examines the permanence of labor force withdrawal. Evidence bearing on this question has already been discussed. In Section I, estimates of the mean duration of labor force withdrawal for various demographic groups were presented. The estimates were surprisingly low, ranging from 4.7 months for male teenagers, to 5-1/2 years for women over 60 . Even for males over the age of 60 , the mean duration was only 2.8 years. This average of course includes all of those who retire permanently. However, mean durations may be deceptive, since the distribution of spell lengths may be extremely assymetric. In order to deal with this possibility, this section presents estimates of the proportion of those who leave the labor force who return within a year.

In deriving these estimates, we rely on the gross changes data and unpublished BLS data on the number of people outside the labor force who have worked within the past 12 months. If all of those who withdrew remained outside the labor force for more than a year, the number outside 
the labor force with recent experience should equal the total of the previous 12 monthly flows. To the extent that the flow out of the labor force exceeds the number outside the labor force with recent experience, we can infer that labor force re-entry has taken place. We define re-entry rates as:

$$
R_{i}=1-\left[\frac{N^{*}}{\sum_{t=1}^{12} F_{l n}^{i}}\right]
$$

where $\mathrm{N}^{*}$ is the total number of those outside the labor force who have been in the labor force within the past 12 months, and $F_{1 n}^{i}$ is the monthly flow out of the labor force for the $i^{\text {th }}$ demographic group.

A data problem makes it necessary to calculate two rates. Ideally one would want to compare the number with recent labor force experience to the outflow. The data provide, however, only the number with recent employment experience. Hence, the appropriate calculation is unclear. Many of those with work experience within the preceding 12 months enter the $\mathrm{N}$ state following a spell of unemployment. Thus $\mathrm{F}_{\text {en }}$ understates the extent of labor force withdrawal. On the other hand, some of those who left unemployment by withdrawing from the labor force within the past year did not work during the year, so $F_{\text {en }}+F_{\text {un }}$ overstates the appropriate flow. 12

Before examining the re-entry rates presented in Table 5 it is important to emphasize their meaning. We have estimated the proportion of those who exited the labor force within the last 12 months who have re-entered the labor force as of a given moment. This figure is certain to underestimate the proportion of labor force exiters who return within 12 months. Many of those who left the labor force within the past 12 months, and who are now outside the labor force, will return within a year from their date of labor force withdrawal. The calculations presented 
Table 5

Rates of Labor Force Re-Entry - 1974

Demographic

Groups

\author{
Re-Entry Rate I
}

.738

.721

.641

.691

.708

.718

.55

.723

.723

.699
Re-Entry Rate II

.819

.798

.795

.722

.794

.801

.671

.836

.741

.771

Note: Rate $I=(1-($ NILF*/EXITE $))$ where NILF* $=$ NILF but worked last year. EXITE = number of labor force exits from employment in last year.

Rate II $=(1=$ NILF* $/$ EXIT $))$ where EXIT $=$ total number of exits from the labor force in last year.

Source: Adjusted gross flows data (see Table 1) and unpublished Bureau of Labor Statistics tabulations on persons not in the labor force. The calculation is based on annual averages of monthly figures. 
here are thus very conservative estimates of the re-entry rate. Some indication of just how conservative may be garnered from the observation that 55 percent of those now out of the labor force who worked within the past 12 months intend to return to work within a year.

Even the most conservative estimates found for Re-entry Rate I are extremely high. For all demographic groups except women 20-24, almost two-thirds of those who left the labor force within the past year have returned. The more realistic but probably still conservative estimates of Re-entry Rate II approach 80 percent. Even for males over 60 , close to 70 percent of those who withdraw from the labor force appear to return within a year.

These estimates are borne out by the intentions of those outside the labor force. Unpublished data provided by BLS suggests that almost 45 percent of those out of the labor force who worked within the previous year intend to return to work within a year. ${ }^{13}$ Since those most likely to re-enter are least likely to be observed outside the labor force, these figures are expected to greatly underestimate the actual re-entry rate. The data do not make possible any direct separate calculation of the rate of re-entrance for those who leave the labor force from unemployment. It seems reasonable to conjecture that the re-entry rate for those leaving unemployment would be, if anything, greater than the re-entry rate for those leaving employment. The BLS data indicate, for example, that among discouraged workers, the proportion intending to return within a year is almost twice that for the total NILF category. Furthermore, regression of the probability of labor force entrance on the share of recent exits from unemployment suggest that the re-entry rate is greater for those who leave the labor force after being unemployed. 
In sum, we are led to conclude that the great majority of those who leave the labor force after being unemployed return within a year. About 75 percent of those who left the labor force within the previous year have returned as of any given moment, This estimate is too low because it ignores all of those who will return within a year from their time of withdrawal, but have not yet returned. Moreover, the available evidence suggests that unemployed leavers are more likely to return than other leavers. Correcting for these two biases conservatively suggests to us that the true re-entry rate approaches 90 percent.

The extremely high rates of labor force exit and entrance suggest that the conventional view of those unemployed due to re-entrance may be very misleading. Re-entrants are traditionally portrayed as people trying to return to work after a long hiatus, or secondary workers with weak job attachment looking for summer, part-time or temporary work. ${ }^{14}$ The welfare significance of this form of unemployment is therefore downgraded. Yet it seems likely that many of the re-entrants have experienced only quite brief spells outside the labor force. It may be more appropriate to view this group as representing long-term unemployment rather than labor force turnover or transition after a long absence. We examine this conjecture in the next section.

\section{IV}

In this section we briefly examine re-entry unemployment to determine whether re-entrants evince patterns of behavior consistent with long-term unemployment. The data come from the Job Search supplement to the May 1976 CPS. Unemployed respondents were asked questions about their 
job search activity during the current spell of unemployment. The survey provides a good deal of information about work intentions, work experience and, for re-entrants, permits a rough calculation of the time spent out of the labor force prior to re-entry.

Table 6 presents data on the characteristics of re-entrants. In line la we examine the importance of re-entry unemployment for different demographic groups. In lines $l b$ and lc the share of each demographic group in re-entrant and total unemployment is presented. The data indicate that those groups most likely to end a spell of unemployment by withdrawing from the labor force -teenagers and adult women - are an important source of re-entry unemployment. Re-entry is much less important among primeaged men, where job losers make up 75.5 percent of the unemployed. A comparison of lines $1 b$ and lc suggests that, except for prime-aged males, the demographic composition of re-entrant unemployment is very much like that for total unemployment. Female teenagers, for example, account for 10.4 percent of all unemployment and comprise 10.5 percent of re-entrants. Prime-aged women account for 23 percent of unemployment and 28 percent of re-entrants. Males 20-24 comprise 13.1 percent of total unemployment and 12.4 percent of re-entrants. We are led to conclude that women and teenagers comprise a large share of re-entry unemployment because they comprise a large share of the unemployed.

While the demographic composition of re-entry unemployment is consistent with the evidence on propensities to exit and enter presented earlier, it is of importance to identify how long re-entrants have been out of the labor force, and to determine the extent to which re-entrants have weaker job attachment than the unemployed generally. These issues are examined in lines $2-4$. In line 2 , we present a cumulative distribution 


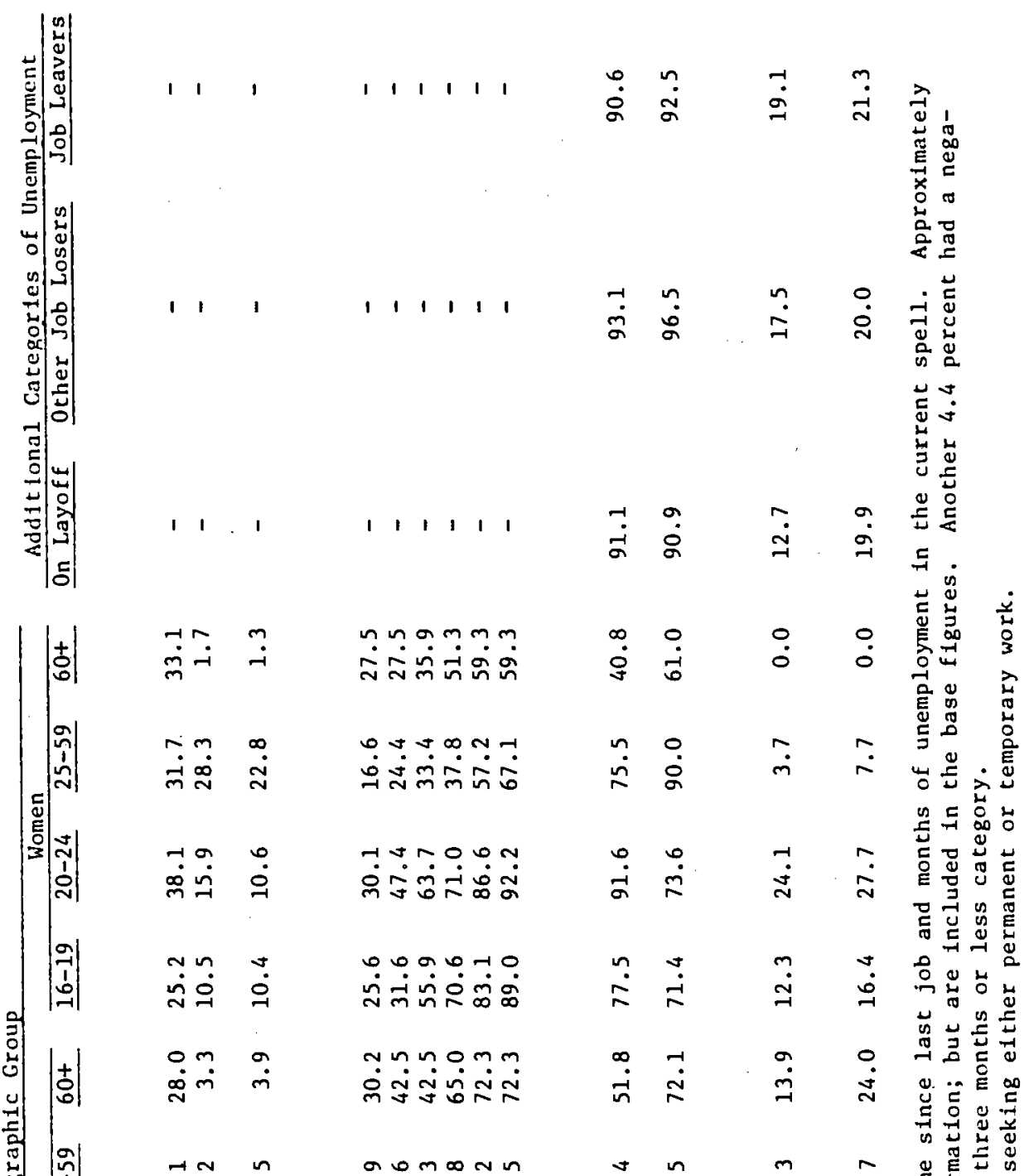

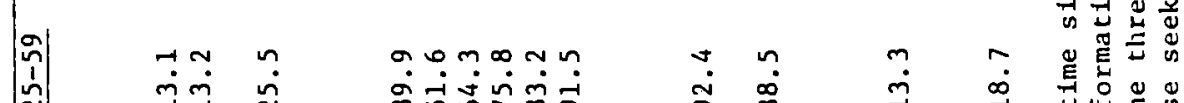

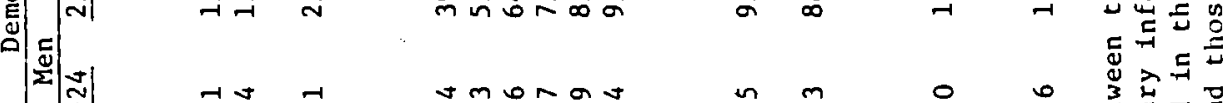

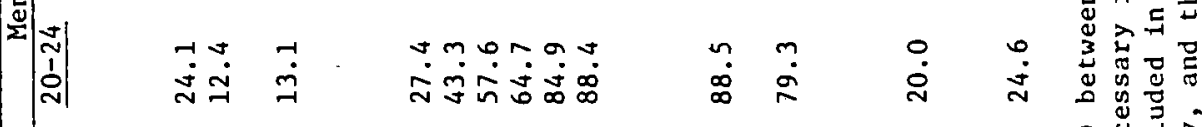

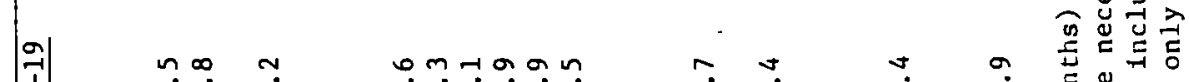

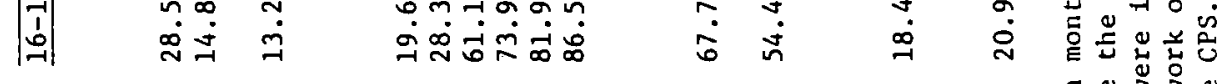

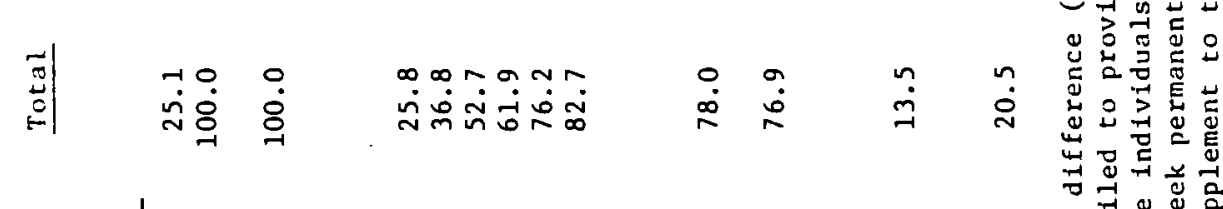

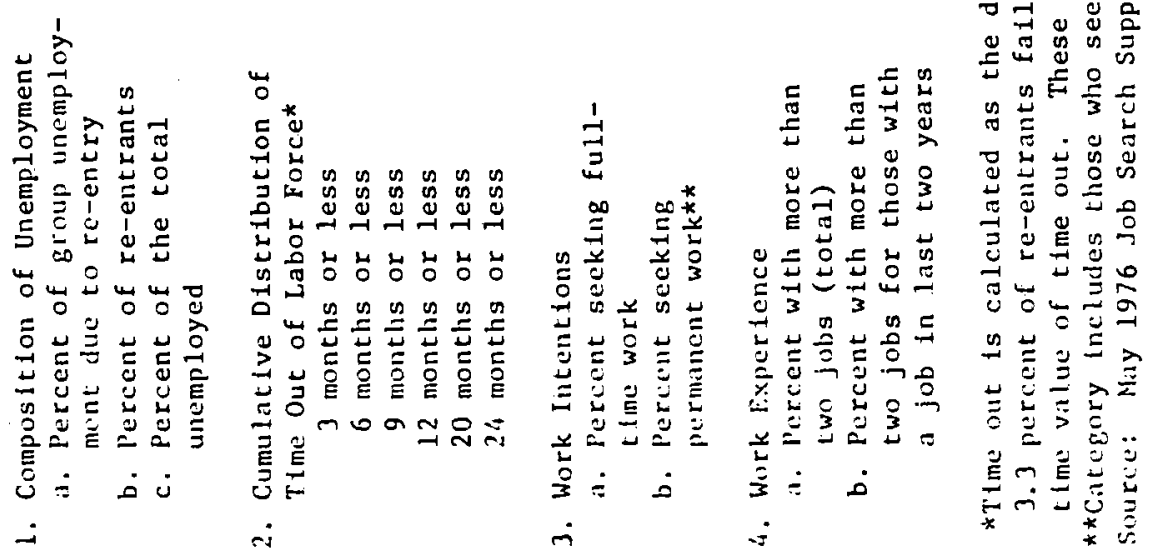


of time between the last job and the beginning of the current spell of unemployment. Because those currently unemployed may have experienced more than one spell of unemployment, this measure overstates time spent out of the labor force. Even with this conservative measure, we find that 25 percent of re-entrants have been out of the labor force less than three months and that 62 percent return within a year of exit. Those returning after an absence exceeding two years make up less than 18 percent of all re-entrants.

Similar patterns emerge across demographic groups. Except for prime-age women, the proportion reporting time out of the labor force of less than a year lies between 65 and 75 percent. Among prime-age males, for example, 40 percent have been out less than three months, while 75 percent have been out less than a year. Only 8.5 percent report being out of the labor force longer than two years. The view of re-entry unemployment which stresses long absence is of any importance only for prime-aged females where only 38 percent report being out of the labor force less than a year. Even in this group, however, close to two-thirds of the returnees were out of the labor force less than two years.

Return to the labor force within a year of exit seems to be the dominant pattern of labor force transition among re-entrants. The evidence suggests that the views of re-entry unemployment which stress return after an extended absence fail to capture the central tendency in the data. The extent to which re-entrance occurs because of weak job attachment and frequent turnover is examined in lines 3 and 4 . Whether one looks at desire for full-time work or job instability, the general thrust of the data is that re-entrants are not much different than those unemployed for other reasons. The data on work intentions, for example, 
indicate that the majority of re-entrants are looking for permanent, fulltime jobs. Even among teenagers, fully 72 percent are seeking full-time employment. Among prime-aged adults, the intentions of re-entrants are very similar to those of job losers and leavers. A similar finding emerges from the data on work experience prior to the current spell of unemployment.

In line $4 \mathrm{a}$ we find that about 13.5 percent of re-entrants report having had more than two jobs in the last two years, a proportion only slightly greater than that found among those on layoff. If we make the calculation after excluding those who have not worked within the last two years and those who failed to answer the questions (line 4b), re-entrants are found to have no more job instability than job losers or leavers. Indeed, there is a surprising degree of uniformity across demographic groups and among the unemployed as a whole. All groups report about 20 percent with more than two jobs.

Our brief examination of the work experience and work intentions data suggests that on average, most re-entrants have as much job attachment as people unemployed for other reasons. Most are not seeking temporary or part-time work, and of those who have worked within the last two years, over 80 percent have held one or two jobs during that period. Measured by number of jobs held, job instability is no less prevalent among job losers and leavers. The evidence on time out of the labor force and the findings in lines 3 and 4 suggest that re-entry after extended absence and extensive movement between jobs are not dominant factors in determining re-entry unemployment. 
Evidence in previous sections suggests that 70 percent of unemployment is accounted for by labor force transitions. We have found that labor force exit is frequent and temporary, with very high rates of re-entry within a year of withdrawal. An important implication of the analysis is that true spells of unemployment are much longer than those estimated from monthly data. The annual March Work Experience Survey provides an opportunity to corroborate this view of unemployment. If it is correct, and time out of the labor force between spells of unemployment is actually almost equivalent to time unemployed, then it seems reasonable that those whose period of unemployment is broken by a short spell outside the labor force will report retrospectively only one spell of unemployment. Thus, the number and duration of spells reported in the work experience survey ought to exceed those reported monthly. Emphasis on work experience also leads us to focus on total weeks of unemployment per person rather than weeks per spell.

These issues are examined in Tables 7 and 8 using work experience data from 1974 and 1976. In Table 7 we present a comparison of the total number of spells of unemployment reported in the monthly CPS, and the Annual Work Experience Survey. The data are presented in raw form in line 1 , and as a fraction of total labor force participants in line 2 . Examination of the column containing data for the total work force reveals a much larger number of total spells in the monthly data. In 1976, for example, the Work Experience Survey reports 24.5 percent fewer spells. Much of the difference comes from teenagers, for whom labor force 
Table 7

Comparison of Total Number of Unemployment Spells from the Work Experience Survey and the Month1y CPS - 1974, 1976

\section{Spe11 Measure}

1. Tota1 number of spe11s

(in thousands)

a. Work experience survey

$$
\begin{aligned}
& 1974 \\
& 1976
\end{aligned}
$$

b. Month1y CPS

\begin{tabular}{|c|c|c|c|c|}
\hline \multirow[b]{2}{*}{ Tot } & \multirow{2}{*}{\multicolumn{2}{|c|}{ Men }} & \multicolumn{2}{|c|}{ Women } \\
\hline & & $20+$ & $\overline{16-19}$ & $20+$ \\
\hline
\end{tabular}

$$
\begin{aligned}
& 1974 \\
& 1976
\end{aligned}
$$

2. Spe11s per labor force participant

a. Work Experience Survey

$\begin{array}{llllll}1974 & .24 & .43 & .23 & .37 & .21 \\ 1976 & .24 & .38 & .23 & .37 & .21 \\ & & & & & \\ 1974 & & & & & \\ 1976 & .29 & .88 & .20 & .87 & .25 \\ & .31 & .93 & .22 & .96 & .26\end{array}$

Note: To insure comparability, the labor force estimate in line 2 was taken from the Work Experience Survey and was the same for both groups. Total spells from the Work Experience Survey were estimated from Table B-12 (1974) and C-1 (1976) as follows: We first calculated total reported spells as the sum of number reporting one spell plus twice the number reporting two spe11s plus 3.5 times the number reporting 3 or more spells; those who were unemployed but did not work were given 1 spell. We then subtracted those spells begun in the previous year to get total spells. Total spells from the monthly data were estimated as $\mathrm{F}_{\mathrm{nu}}+\mathrm{F}_{\mathrm{eu}}$ from the gross flows data. 
Table 8

Duration of Unemployment from Work Experience Surveys and Gross Flows Data - 1974, 1976

\section{Measures of Duration}

1. Average duration of completed spells

begun in:

$$
1974
$$$$
1976
$$

2. Average weeks of unemployment per person with unemployment in:

$$
\begin{aligned}
& 1974 \\
& 1976
\end{aligned}
$$

3. Percent of labor force with more than 26 weeks of unemployment

$$
\begin{aligned}
& 1974 \\
& 1976
\end{aligned}
$$

4. Percent of unemployment accounted for by those with more than 26 weeks of unemployment
Demographic Group

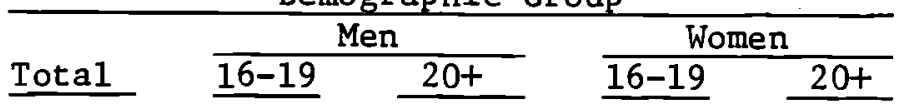

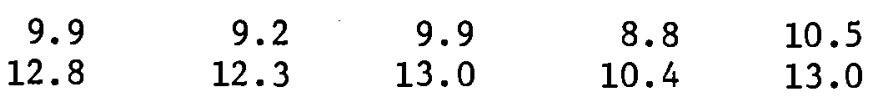

$\begin{array}{lllll}12.5 & 12.4 & 13.3 & 10.4 & 11.9 \\ 16.1 & 15.8 & 17.5 & 12.2 & 15.1\end{array}$

1974

1976

$\begin{array}{lllll}2.2 & 4.4 & 2.1 & 3.1 & 2.0 \\ 3.9 & 6.7 & 3.0 & 4.1 & 3.3\end{array}$

Note: Data in lines 1-2 are in weeks. Total weeks is calculated from Tables B-12 and B-20 of the 1976 WES and Tables C-1 and D-1 of the 1974 WES, using midpoints of the unemployment weeks categories. In making the calculation we assumed the distribution of weeks of unemployment of 18-19 year olds without work experience, but with unemployment was equal to that for 18-24 year olds. Total spells is calculated as the sum of the number of people with one spell, twice the number with two spells and 3.5 times the number with 3 or more spells; we assumed that those with unemployment, but without work, had one spell. In line 2 average duration $=\left(T_{t}+W_{t+1}-W_{t}\right) /$ $\left(S_{t}-J_{t}\right)$ where $T=$ total weeks, $S=$ total spells, $J=$ number of people unemployed in December of year $t-1$ who are still unemployed in January of $t$, $\mathrm{W}_{t}=\mathrm{J}_{t} \cdot \mathrm{DU}_{t}$, where $\mathrm{DU}$ - average duration of unemployment in year $t$; for 1976, we used $\mathrm{DU}_{76}$ to get $\mathrm{W}_{77}$. Total persons with unemployment in year $t$ is taken from the same tables as total weeks and total spells. Lines 4 and 5 were calculated from WES tables (B-12, C-1). 
transitions are a particularly important source of unemployment. We also find fewer spells reported retrospectively among adult women, while adult men report more unemployment experiences in the March survey. The larger number of spells for adult men may reflect the greater incidence of short (1-3 week) spells of unemployment from temporary layoff among adult men which are not picked up in the monthly data, but are reported in the Work Experience Survey.

It appears from Table 7 that time out of the labor force between spells of unemployment is viewed in retrospect as time unemployed. The evidence on number of spells thus suggests that estimates of duration from the monthly data should be shorter than estimates from the March survey. This issue is examined in Table 8 . In line 1 we present estimates of average duration adjusted for spells begun (completed) but not completed (begun) in the year. Failure to adjust for incomplete spells biases duration estimates downward. The adjustment used here involves excluding weeks of unemployment associated with spells begun in the previous year, and adding weeks of unemployment associated with spells completed in the following year. The adjustment results in a moderate increase in estimates of mean duration. The estimate for all unemployed in 1975 is 9.9 weeks, and 12.8 weeks in 1976 . The adjustment has a similar effect in the disaggregated demographic groups. These estimates are about 10-20 percent higher than corresponding estimates from the monthly data.

The discrepancy between estimates of average duration from the Work Experience Survey and from monthly data provides further evidence that many of those who leave the labor force from unemployment think of themselves as being unemployed, even after withdrawal. The evidence implies 
that job finding was more difficult than might be inferred from published data from the monthly CPS. This observation is further substantiated in line 2 where weeks of unemployment per person rather than per spell is presented. These data provide a different picture of the burden of unemployment than that provided by conventional estimates of weeks per spell. In 1974, for example, adult males with unemployment in the year experienced, on average, 13.3 weeks of unemployment. In 1976, weeks per person jumped to 17.5 for adult males, and to 15.1 for adult women.

The relatively large number of weeks per person estimated in line 2 might be due to a concentration of unemployment among a relatively small group. The concentration of unemployment is examined in lines 3 and 4 of the table. We present the proportion of those with work experience and of total unemployment accounted for by persons with 26 or more weeks of unemployment. Among men 20 and over, for example, only 3.0 percent experienced more than 26 weeks of unemployment in 1976, but this relatively small group accounted for 52.1 percent of total unemployment. A similar pattern emerges in other demographic groups. In aggregate, 3.9 percent of those working or looking for work experienced more than 26 weeks of unemployment, and accounted for 50.4 percent of total unemployment. Even this estimate understates the true extent of chronic joblessness because it ignores those who withdraw from the labor force.

VI

The results presented in this paper challenge what has in recent years become the conventional wisdom regarding unemployment. They suggest that analyses focusing on the brevity of typical spells of unemployment and high turnover among the unemployed obscure more than they reveal. Much of 
what appears to be turnover among the unemployed represents labor force withdrawal. Short durations may not indicate the easy availability of jobs, but rather workers' decision to abandon search quickly. Our results suggest that traditional estimates of the length of a completed spell understate by close to 100 percent, the duration of a spell for a worker who is unwilling to leave the labor force. Moreover, many of those who withdraw from the labor force are in situations effectively equivalent to those of unemployed persons. They appear to be sensitive to available job opportunities, and to return to work within a few months after leaving the labor force. The spells of actual as opposed to measured unemployment are thus even longer for this group than for those who return to work directly from unemployment. Indeed, the probability that a labor force entrant will find a job within the first month of unemployment, far exceeds (by almost 300 percent) the likelihood of an unemployed person's finding a job within a month. Among the small portion of labor force entrants who do not find a job before the next monthly survey, our evidence suggests that the vast majority have had recent work experience. The common depiction of re-entrants as comprised largely of teenagers, and those returning after long hiatus from work is not true.

We interpret this evidence as indicating that the welfare significance of unemployment has been greatly underestimated. Attractive jobs are not nearly as available as the short duration of unemployment has suggested. Retrospective evidence indicates that much of unemployment is experienced by those with long-term spells. Further, the data indicate the existence of a substantial number of hidden unemployed, who are counted as not in the labor force despite having recent work experience and 
imminent plans to return to work. Conventional dismissals of re-entrant unemployment as frictional also seem to be inappropriate. Re-entrants are in fact frequently completing rather long spells of actual unemployment even though their measured spells are quite brief. Hence, they may be amongst the more serious unemployment problem.

There is another possible interpretation of our results. High flows into and out of the labor force might reflect the movements of a relatively small number of workers with little work attachment. Movements out of the labor force may be voluntary, and not result from inability to find employment. While we do not doubt that some of the large observed flows do represent this phenomenon, it seems unlikely that it can account for most of it. The proportion of workers who leave the labor force rises with the length of unemployment. This is consistent with the view that many of those who withdraw do so because of discouragement. It is hard to understand why a person with very weak job attachment would plan to search for several months and then to leave the labor force.

Moreover, the vast majority of discouraged workers appear to have been recent labor force exiters, with plans to return soon. In 1974, about 39.4 percent of the discouraged workers had left the labor force within the past year. Of those, over 88 percent intended to return within a year. Most left the labor force for economic reasons. The total of discouraged workers equals about one month's flow from unemployment out of the labor force, providing direct evidence that many of the withdrawals are due to discouragement.

Future research is necessary to provide more precise estimates of the magnitude of the phenomena discussed in this paper. More important, the results suggest that attention must be devoted to the development of 
theories explaining labor force transitions. The option of abandoning search is not incorporated in usual models of search unemployment. Likewise, the timing of decisions to enter the labor force which accounts for the vast majority of new employment is not well understood. The development of such theories will be greatly aided by newly available monthly longitudinal data on the unemployed. 


\section{Footnotes}

1. See, for example, Feldstein (1973), Perry (1972) and the last several Economic Reports of the President.

2. Modern work with the gross flows data has been pioneered by the Urban Institute. Examples of recent research include Toikka (1976), Smith (1977), and Toikka, Scanlon and Holt (1977). See also papers by Marston (1976) and Hall (1972). There are several limitations of the gross flows data, summarized in Hilaski (1968). First is the set of consequences of mismeasurement. Errors in measurement will lead to systematic overestimates of labor force flows. Second, data on gross changes are not available for those in their. first or fifth month in the sample. Since there are systematic differences in reporting between rotation groups, the changes data do not correspond to the stock data. The Urban Institute has developed a regression procedure for adjusting the changes data to make it consistent with the published stock data. This study uses the flows data as adjusted by them. Researchers there report tht the adjustments are typically not large enough to affect substantive conclusions. A detailed discussion of the adjustment procedure may be found in Vanski (1975).

3. The magnitude of the monthly flows is well known, and has been documented in several places. See, for example, Smith (1972). Other references which have noted the importance of labor force transitions include Perry (1972), Hall (1972) and Marston (1976).

4. This identity may be verified quite easily. Let $g_{i}$ (s) be the density function, for the lengths of completed spells of $i$ state $i$. Then the mean duration of a completed spell $\mathrm{D}_{i}$ may be represented as:

$$
D_{i}=\sum_{s=0}^{\infty} s g(s)
$$

If we allow $1-G(s)$ to represent the cumulative density of completed spells, then (6) implies that:

$$
D_{i}=\sum_{s=0}^{\infty} G(s)
$$
If we let the flow into state $i$ in each period be represented by $F_{i}$,
the definition of $G(s)$ implies that:

$$
S_{i}=F_{i} \sum_{s=0}^{\infty} G(s)
$$

Since the steady state assumption implies that the number of entrants into state $i$ must equal the number who exit, it follows from the definition of $P_{i i}$ that: 


$$
\left(1-P_{i i}\right) S_{i}=F_{i}
$$

Substituting equations (C) and (D) into (B) yields the desired result. It should be emphasized that nothing was assumed in this derivation about either duration dependence or heterogeneity. The result here holds for any density $g(s)$ of completed spell lengths. The result found here closely parallels the well-known renewal theorem. The result here depends critically on the steady state assumption. Since this analysis relies on annual average probabilities, any deviation from a steady state is likely to be small. This conclusion was confirmed by a procedure described below which does not rely on steady state assumptions.

5. All of the estimates of the duration of unemployment presented here are potentially subject to an important upward bias. Individuals are observed only monthly. Hence, many short spells of unemployment fall between observations and are missed. In order to estimate the magnitude of this bias we used unpublished estimates of the weekly flow into unemployment to calculate duration. The results are not significantly different from those presented here. This may be the result of large reporting errors for short spells of unemployment which bias upwards the estimates from weekly data.

6. A thorough discussion of these issues is contained in Salant (1977).

7. This figure matches almost exactly the average proportion of exiters as calculated from the changes data.

8. See, Rao (1965) and Swamy (1970), for a discussion of models in which the coefficients are random.

9. The equation was estimated using ordinary least squares. Equation (19) suggests that if the $v_{\text {. }}$ do not have equal variances, correction for heteroscedasticity woułd be appropriate. We tested for heteroscedasticity by regressing the residuals on the $S_{i}$. The null hypothesis of no heteroscedasticity was easily acceptèd. The results are available on request from the authors.

10. The calculation was performed at the average value of $U$ and the $S_{i}$. The results suggest that the patterns noted here do not vary greatly over the cycle.

11. These are calculated from the variances and covariances of the coefficients of $s_{i}$ and $s_{i} U$. The standard error is evaluated at the mean.

12. It seems likely that the actual flow is close to $F_{\text {en }}+F_{\text {un }}$, since most of those who became unemployed during a 12 -month period un have work experience during the period.

13. Tabulations are available from the authors on request.

14. A characterization along these lines can be found in Economic Report of the President 1975, pp. 88, 102. 


\section{References}

Bureau of Labor Statistics. Work Experience of the Population, 1974, 1976.

Feldstein, Martin. "Lowering the Permanent Rate of Unemployment," Study prepared for the use of The Joint Economic Committee, U.S. Congress, Washington, September 1973.

Fall 1973 .

. "The Economics of the New Unemployment," Public Interest,

Hall, R. E. "Turnover in the Labor Force," Brookings Papers on Economic Activity, 3:1972, pp. 709-764.

Hilaski, H. "The Status of Research on Gross Changes in the Labor Force," Employment and Earnings, October 1968.

Marston, Stephen. "Employment Instability and High Unemployment Rates," Brookings Papers on Economic Activity, 2:1976.

Perry, George. "Unemployment Flows in the U.S. Labor Market," Brookings Papers on Economic Activity, 2:1972.

Rao, C. R. "The Theory of Least Squares When the Parameters are Stochastic," Biometrika, 1965, pp. 447-458.

Salant, Stephen. "Search Theory and Duration Data: A Theory of Sorts," Quarterly Journal of Economics, 1977, pp. 39-57.

Smith, Ralph E. "A Simulation Model of the Demographic Composition of Employment, Unemployment and Labor Force Participation," in, Research in Labor Economics, Vol. 1 (1977), R. G. Ehrenburg (ed.).

Swamy, P. A. V. B. "Efficient Inference in a Random Coefficient Regression Model, "Econometrica, 1970, pp. 311-323.

Toikka, R. S. "A Markovian Model of Labor Market Decisions by Workers," American Economic Review, 1976, pp. 821-834.

, Scanlon, W. J. and Holt, C. C. "Extensions of a Structural Model of the Demographic Labor Market," in Research in Labor Economics, R. G. Ehrenburg (ed.).

Vanski, Jean. "Recession and the Employment of Demographic Groups, Adjustments to the Gross Changes Data," unpublished paper. 